\title{
A framework for self-determination in massive open online courses: Design for autonomy, competence, and relatedness
}

\author{
Neil I. Martin \\ University of Southern Queensland \\ Nick Kelly \\ Queensland University of Technology, University of Southern Queensland \\ Peter C. Terry \\ University of Southern Queensland
}

In this paper, we propose a framework for the design of massive open online courses (MOOCs) based upon the principles of self-determination theory, which posits a relationship between intrinsic motivation and the basic psychological need for autonomy, competence, and relatedness. We also report the results of design-based research that evaluates the application of the framework to a MOOC titled "Elite Sport Performance: Psychological Perspectives". Satisfying basic psychological needs is theorised as central to course design in order to foster intrinsic motivation, optimise engagement, and improve the retention of course participants. We chronicle the design, implementation, and evaluation of the course, providing examples of support features and learning activities. The course was offered over a period of four months, receiving more than 1000 registrations from across the world. Engagement measures, completion indices, and intrinsic motivation scores are reported as well as sample testimonies from learners. Results offer preliminary evidence that a design framework incorporating selfdetermination theory has utility in the development of MOOCs that successfully engage learners.

\section{Introduction}

The dynamics of engagement and motivation within massive open online courses (MOOCs) is an area of great interest for learning designers and researchers in the learning sciences (Ferguson et al., 2015). MOOCs represent a particular learning context in which barriers to access are low when compared to traditional higher education but dropout rates are typically high, with median completion rates of just $12 \%$ found in a metaanalysis of 221 courses (Jordan, 2015). In order for MOOCs to achieve their potential, a mature understanding of how to design for this medium is required (Downes, 2009). Our paper focuses on the motivational needs of participants in MOOCs and how courses can be designed for sustained engagement. We address the question of how engagement can be optimised within a learning environment where participants may choose to leave at any time and where dropout is a normative event. To answer this challenge, we apply the principles of selfdetermination theory (Deci \& Ryan, 2000), an established theory of motivation, behaviour, and well-being that aims to explain the conditions under which humans come to act with agency, volition, and engagement.

Self-determination theory is a psychological theory of motivation that has received increasing interest in the MOOC literature (e.g., Khan et al., 2017) and many other disciplines due to its utility in explaining engagement phenomena. In diverse domains, the application of principles from self-determination theory have been shown to lead to increased intrinsic motivation (e.g., Guay, Ratelle, \& Chanal, 2008; Ng et al., 2012). However, to the authors' knowledge, no work has yet aimed to help learning designers apply the theory to the design and creation of MOOCs. In this paper, we offer an account of how the application of selfdetermination theory by learning designers might benefit learners. The theoretical foundations for a design framework are described and assessed via the development, implementation, and evaluation of a MOOC in sport psychology, titled "Elite Sport Performance: Psychological Perspectives" (Terry \& Martin, 2015). Selfdetermination theory was chosen because components of the theory have a focus on the internal and selfcongruent needs of the individual. We assume that individuals who sign up for a MOOC are at a minimum expressing an interest in taking part, and therefore course developers would wish to foster and maintain the 
intrinsically motivated engagement of course participants. In addition, self-determination theory specifies the conditions in which interest and enjoyment may be supported or thwarted, and therefore was selected as a relevant motivational theory to inform the design of a MOOC. We adopted a design-based research methodology to formulate a theory-based framework, and then test the framework in a real-world learning scenario. Our findings provide preliminary evidence to suggest that self-determination theory may be well suited to the design of MOOCs.

\section{Background}

A central challenge in the educational design of MOOCs is the necessity to motivate and engage learners within an environment that can be exited with a single click (Barak, Watted, \& Haick, 2016; Salmon, Pechenkina, Chase, \& Ross, 2017). No learning design strategy can guarantee optimal engagement, although there has been some success using networked learning and connectivist approaches (Downes, 2013) as well as applying traditional instructional design techniques to the open online environment (Margaryan, Bianco, \& Littlejohn, 2015). How to design for engagement remains a dynamic and debated space, with a breadth of research in this area (e.g., Gütl, Rizzardini, Chang, \& Morales, 2014; Hew, 2016). However, no clear guide exists for how to design for engagement within MOOCs, which specifically considers the intrinsic and autonomous nature of motivation needed in this particular context. To address this gap in the literature, we advance an argument for self-determination theory as a basis for open online design through targeting "specifiable psychological and social nutrients" (Ryan \& Deci, 2017, p. 82).

\section{Theoretical foundations in self-determination theory}

Self-determination theory is a theory of motivation that specifies the social-contextual variables fundamental to optimal human functioning, growth, and well-being. The theory postulates that humans are innately agentic and information seeking, with a natural tendency to explore their environment, learn about their world, and integrate new experiences into an organised and coherent sense of self. The theory is utilised in many areas of applied research, including education (e.g., Reeve \& Lee, 2014), organisational studies (e.g., Gagné et al., 2015), sport and exercise psychology (e.g., Matosic et al., 2017), psychotherapy (e.g., Britton, Patrick, Wenzel, \& Williams, 2011), health and medicine (e.g., Niven \& Markland, 2016), and recreational activities (e.g., Rogers, 2017).

Early work in self-determination theory examined motivational processes and in particular how reward contingencies (e.g., money) and the social environment (e.g., giving proximal feedback) affect intrinsic motivation (Deci, 1975). Intrinsic motivation can be defined as undertaking an activity for its perceived inherent qualities or, put simply, because it is interesting and enjoyable (Deci, 1975; Ryan \& Deci, 2017). In an open online learning environment such as a MOOC, intrinsic motivation is an important psychological construct to consider, because the barriers to access are relatively low when compared to traditional forms of education (e.g., no course fees). Furthermore, engaging with such courses from a learner perspective is a volitional activity and the learner can choose to disengage with minimal penalty.

Self-determination theory places an emphasis on individual "sense of choice, volition, and commitment" (Deci \& Ryan, 2010, p. 2), which is defined as autonomy, one of three basic psychological needs along with competence and relatedness. These universal needs are the psychological "nutriments" (Deci \& Ryan, 2002, p. 6) that are essential throughout life for "ongoing psychological growth, integrity, and well-being" (Deci \& Ryan, 2000, p. 229). A vast body of empirical research in self-determination theory has demonstrated that when these needs are satisfied, they predict a range of positive functional outcomes in terms of quality of motivation, self-regulation, learning, organisation and integration, vitality, and well-being.

Optimised social environments that satisfy basic psychological needs (e.g., opportunities for choice, to be effective and gain mastery, or that involve close interpersonal relationships), are said to provide needs support. In relation to intrinsic motivation, self-determination theory postulates that social and environmental conditions that support autonomy, competence, and relatedness will enhance intrinsic motivation, whereas conditions that foil these basic psychological needs will undermine intrinsic motivation (Ryan \& Deci, 2017). We suggest that the consequences of diminished intrinsic motivation in the particular context of a MOOC will 
lead to a loss of persistence and eventual dropout from the course. People engage with MOOCs against the backdrop of other salient aspects of their life, such as work or other studies, and therefore optimising design for intrinsic motivation becomes even more important given that the chances of withdrawal are very high.

The first basic psychological need articulated in self-determination theory is the need for autonomy. Autonomy is characterised by authentic behaviours and actions that emanate from and are fully endorsed by the self (Ryan \& Deci, 2017). It sits in contrast to heteronomy in which behaviours are regulated by controlling forces either internal (e.g., guilt) or external (e.g., rewards or punishments). When the need for autonomy is satisfied, individuals are more likely to perform at their best (Adie, Duda, \& Ntoumanis, 2008), be creative (Sheldon, 1995), engage and persist with activities (Vansteenkiste, Simons, Lens, Sheldon, \& Deci, 2004), feel psychologically well (Ryan \& Deci, 2001), and form and maintain high-quality social relationships (Deci \& Ryan, 2014). Self-determination theory predicts negative outcomes when no autonomy is experienced, such as reduced interest and persistence, and potentially a host of other undesirable psychological consequences.

The second basic psychological need identified in self-determination theory is the need for competence. Competence relates to an innate need to learn and master new skills and abilities (White, 1959), and to be effective in activities that matter to the individual. Competence as a construct has long been empirically associated with motivation, although the role of autonomy support in enhancing competence differentiates self-determination theory from other motivational theories such as self-efficacy theory (Bandura, 1995), which negates the relevance of autonomy (Niemiec \& Ryan, 2009). More specifically, self-determination theory predicts that competence increases in a social environment that is autonomy supportive, and that feelings of competence will persist over time (e.g., Black \& Deci, 2000). Some of the earliest research findings into intrinsic motivation found strong evidence to support the interaction of autonomy support and competence in sustaining or diminishing intrinsic motivation (Deci, 1975).

The third basic psychological need specified in self-determination theory is the need for relatedness. Relatedness, like autonomy and competence, facilitates high-quality motivation and describes a human need to form close interpersonal relationships (La Guardia \& Patrick, 2008), to feel connected to and care for others (Ryan, Huta, \& Deci, 2008), and to belong to a group (Baumeister \& Leary, 1995). Relatedness plays both a proximal and distal role in fostering intrinsic motivation depending on the context. Having immediate social connectivity is not a prerequisite for intrinsic motivation in many circumstances. When participating in an activity, one can feel a rich sense of enjoyment and interest without the need for others to be present. However, close attachments and secure relationships do have a supporting function even in singular pursuits.

\section{Self-determination theory in educational settings}

Self-determination theory has been applied in a wide range of educational contexts. Researchers have investigated classroom motivation and engagement (e.g., Ryan \& Deci, 2009), autonomy-supportive versus controlling teaching practices (e.g., Sarrazin, Tessier, Pelletier, Trouilloud, \& Chanal, 2006), parental roles in student learning (e.g., Roth, Ron, \& Benita, 2009), need satisfaction in deep and conceptual learning (e.g., Jang, Reeve, \& Halusic, 2016), and the potentially undermining effect of standardised testing on student motivation and teaching climate (Deci \& Ryan, 2016).

In a higher education context, Sørebø, Halvari, Gulli, and Kristiansen (2009) investigated university and college teacher continuance of e-learning tools in the classroom. They concluded from their experimental findings that the basic psychological need of competence coupled with perceived usefulness is the strongest predictor of usage continuance. In an investigation into a university online course, Chen and Jang (2010) emphasised the importance of ongoing support of basic psychological needs within the learning environment. Their findings suggested that the satisfaction of basic psychological needs had a mediating effect on learning outcomes, presumably by supporting intrinsic or other autonomous forms of motivation. Tschofen and Mackness (2012) noted the conceptual links between autonomy as characterised in self-determination theory and understanding individual behaviours within networked learning contexts. The authors also highlighted limited technology skills and difficulties with the learning interface as factors that may have a negative effect 
on feelings of competence in the online environment. Recently, Marzouk et al. (2016) proposed that learning analytics design should be grounded in self-determination theory to better support self-regulated learning.

In the open education space, research that links self-determination theory to open practice is limited but has the potential to grow, given the philosophical synergies. Simpson (2008), for example, proposed that a substantive motivational theory should be applied to learners in open and distance learning environments, suggesting self-determination theory as a possible contender, and specifically proposing meaningful choice as a key aspect for motivating learners. Others have proposed self-determination theory as an appropriate frame of reference for understanding MOOC engagement (e.g., Hew, 2016), while highlighting the challenges of balancing self-determination and facilitation within the confines of an 8-week MOOC (Beaven, Hauck, Comas-Quinn, Lewis, \& de los Arcos, 2014).

Self-determination theory measures have been used to evaluate basic psychological needs satisfaction in a MOOC environment. Durksen, Chu, Ahmad, Radil, and Daniels (2016) conducted one of the first published evaluations of a MOOC that assessed the satisfaction of basic psychological needs empirically. Findings from Zhou (2016) in a Chinese MOOC context indicated that autonomous motivation (e.g., intrinsic motivation) plays a central role in terms of continuance intention, and therefore learner-centred design approaches should be a priority for designers. Beaven, Codreanu, and Creuzé (2014) assessed levels of intrinsic motivation in a language MOOC using the Intrinsic Motivation Inventory (IMI; Plant \& Ryan, 1985). Perhaps of most relevance in terms of the unique design context of MOOCs, Beaven, Codreanu, and Creuzé (2014) identified factors that created pressure and tension for MOOC participants, including imposed time limits and issues of perceived efficacy.

\section{Methods}

This paper provides preliminary data about the potential for application of principles from self-determination theory to improve participant engagement within a MOOC. The literature attests to high attrition rates in open courses (Veletsianos \& Shepherdson, 2016), and the theoretical explanations for these dropouts suggest that an overarching challenge of learning design for MOOCS is the maintenance of learner motivation and engagement (e.g., de Barba, Kennedy, \& Ainley, 2016). An exploratory design study was conducted in which the principles of self-determination theory were used to inform the design for an open, online course, based upon a framework for how learning design can address the three basic psychological needs of autonomy, competence, and relatedness. The goal of the framework is to articulate specific design considerations for MOOCs to provide a bridge between theory and practice.

Design-based research as a methodology has emerged in response to the challenge in educational research presented by the messiness of the open world and the inability to control variables as one can in a laboratory experiment (Cobb, Confrey, diSessa, Lehrer, \& Schauble, 2003). Design-based research is well suited for the educational paradigm, in which strong theoretical foundations form the basis for the design of learning interventions which can be iteratively reported upon and improved (Barab \& Squire, 2004; Collins, Joseph, \& Bielaczyc, 2004). The present study takes the form of design-based research, where a grounding in theory leads to the development of a framework, which is implemented to establish preliminary results. A MOOC was implemented and results gathered, in the form of course statistics, engagement measures, and participant short answer responses. These results do not allow for generalisation about the utility of the framework beyond "petite generalization" (Stake, 1995, p. 7). However, the study does serve the purpose of design-based research to "advance a particular set of theoretical constructs that transcends the environmental particulars of the contexts in which they were generated, selected, or refined" (Barab \& Squire, 2004, p. 5).

In the present study, we apply self-determination theory to MOOC design principles that, based upon the theory, are likely to lead to higher quality learner motivation and engagement - two key factors in improved retention. We first propose a theory-informed framework for self-determination in MOOC design, and then report on an evaluation of the framework under the conditions of a "live" MOOC. 


\section{A framework for self-determination in the design of MOOCs}

Existing frameworks for MOOC design tend to focus on links between design elements and learning goals and outcomes (e.g., Guàrdia, Maina, \& Sangrà, 2013; Yousef, Chatti, Schroeder, \& Wosnitza, 2014). Terms such as "engagement" and "participation" are frequently used within the MOOC literature, although the design proposals to address them are rarely identified or clearly linked to established psychological constructs. The aim of the proposed framework was to develop actionable design principles that can be used by MOOC learning designers for improving learner motivation, engagement, and retention. The proposed framework for the design of MOOCs (see Figure 1) was developed from the theoretical foundations proposed by self-determination theory, and using the literature on designable elements within MOOCs (e.g., Peters 2014) as well as experience in MOOC design. The process used to develop the framework is described in detail by Martin (2017).

Firstly, the framework gives primacy to autonomy, where course design aims to create a non-pressurised environment that allows the learner to regulate their own learning, work at their own pace, and provide a degree of choice in the learning tasks with which to engage. In the framework, we propose that autonomy is supported through design that:

- offers meaningful choice;

- allows self-paced learning and sets no deadlines;

- limits task imposition and reward contingencies; and

- provides task involvement, immersion, and a sense of presence.

Secondly, growth in perceived competence is developed through features that support the learner to build an understanding of theory, concepts, and applications to be mastered. We propose that competence is supported by design that:

- provides structure, supportive information, and clear task rationales;

- creates an optimal level of challenge;

- gives an indication of progress; and

- provides positive and constructive feedback with unexpected rewards.

Finally, relatedness plays an important role in the proximal fostering of intrinsic motivation. We propose that relatedness is supported by:

- encouraging interaction between course participants;

- having a warm and friendly approach in course communication; and

- taking the internal frame of reference of the learner.

Such design principles are not new to learning designers, although the framework makes an original contribution by identifying how they relate to universal human needs that have been widely investigated in psychological research, and how they can be applied in a systematic and beneficial way within the design of open online learning. 

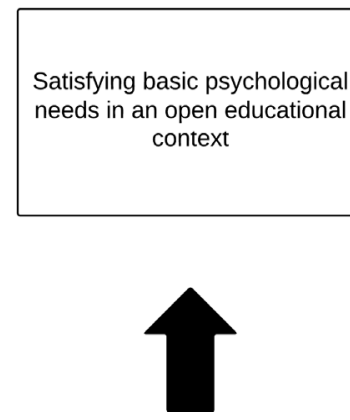

Autonomy support
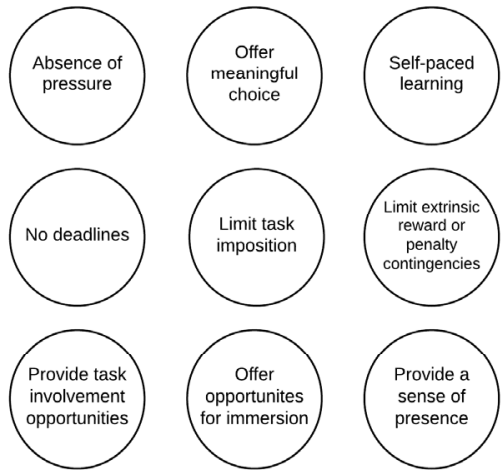

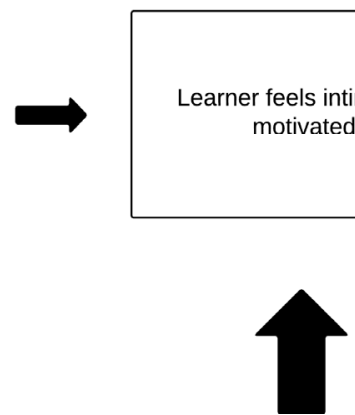

Competence support
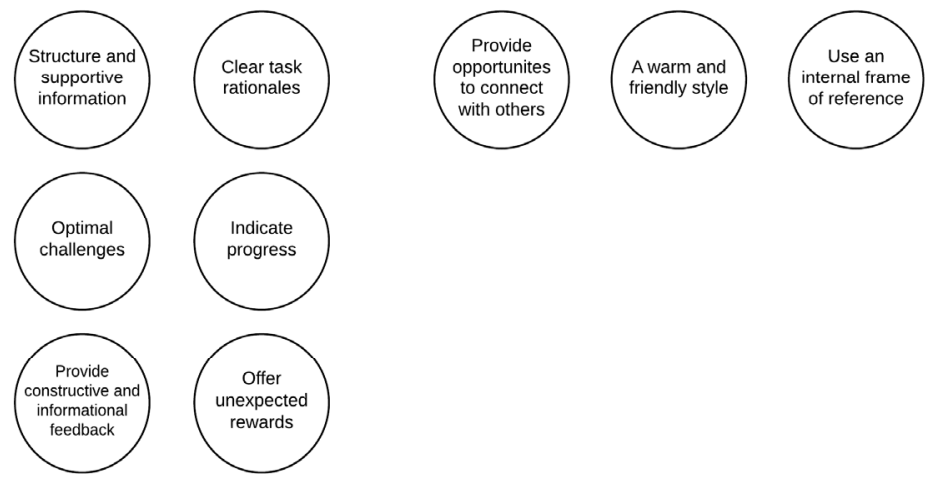

Learner is volitionally

engaged, active, creative, and learns more deeply

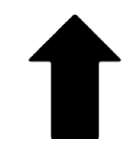

\section{Relatedness} support

Figure 1. Proposed design framework that applies self-determination theory principles to foster intrinsic motivation and drive engagement

\section{Evaluation study}

Preliminary evidence to test the framework is provided via an evaluation of the design, delivery, and analysis of "Elite Sport Performance: Psychological Perspectives", a free and open online course to introduce learners to the psychology of elite sport performance and mental training techniques. The course was created to broaden access and understanding of professional approaches to the psychology of elite sport performance and provide learners with practical understanding of the psychological dynamics of elite sport. It was developed over a 6-month period using the self-determination theory framework described in Figure 1 and was intended to take approximately $40-60$ hours to complete.

The course was hosted on a WordPress platform with scalable server architecture. A commercially available plugin called LearnDash (https://www.learndash.com/) was utilised to provide the learning management functionality. LearnDash has a number of features that made it suitable for this course. First, learning content could be structured to meet the specification mapped out in the planning stages of the course. Second, it could be wholly integrated with other plugins so that, for example, a discussion forum was added to the course. The course was integrated with native WordPress registration features allowing users to easily register and enrol. Third, the learner could sequentially unlock content as they progressed through the course, with the intention of increasing their perceived sense of competence and autonomy satisfaction over time. Finally, for anyone with experience of WordPress development, LearnDash was a relatively easy product to install and integrate with other functionality. The course ran from October 2015 to March 2016. A screenshot showing the look and feel of the course is shown in Figure 2 and an overview of the course structure is provided in Figure 3. The course was designed for learners to understand various psychological skills, techniques, and interventions 
associated with elite performance in sport and later apply them to an authentic learning scenario through the development of a mental training program for a hypothetical athlete.

The course was evaluated using web analytics, surveys of perceived basic psychological needs support, and open-ended feedback from course participants. A comprehensive description of "Elite Sport Performance: Psychological Perspectives" and a comparison of the designed course with a prior offering of the course were reported by Martin (2017). An evaluation of a previous offering of the course reported only sporadic engagement and an extremely high attrition rate, leading us to reconceptualise the course from the ground up. In the present paper we focus on two outcome measures: First, the completion rate of learners taking the course and their level of engagement with the content offered; and second, the post-course survey completed by participants in order to understand learners levels of engagement and evidence of intrinsic motivation driving that engagement. Ethical approval for the research project was provided by the University Human Research Ethics Committee (Approval No. H15REA007).

The various elements of the framework are described sequentially according to their instantiation in the course. The study provides a real-world example of how self-determination theory can inform the design of a course and, we argue, have a positive impact on the motivation and engagement of learners.
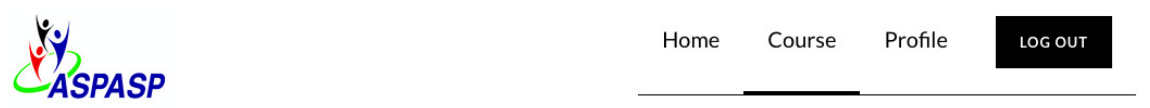

\section{Self-confidence}
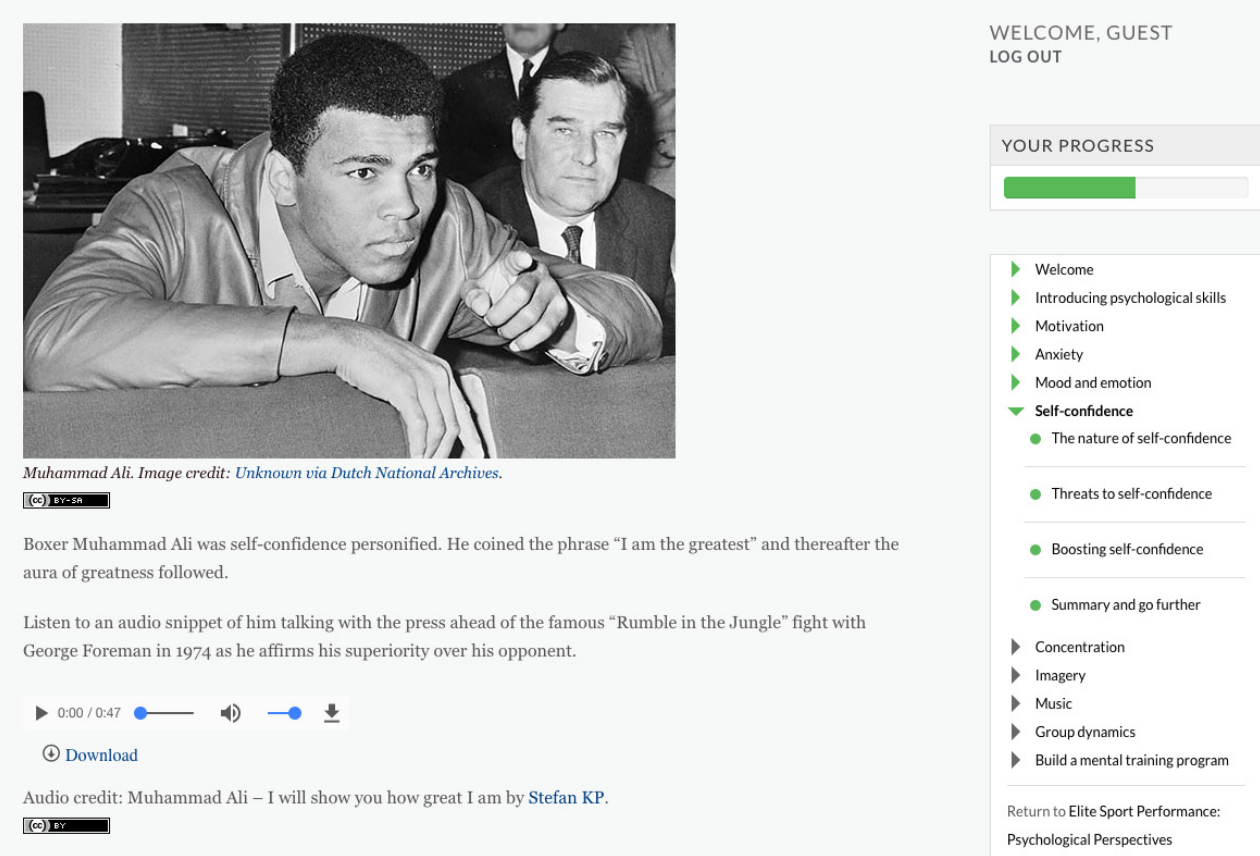

Figure 2. Example course page from "Elite Sport Performance: Psychological Perspectives" 


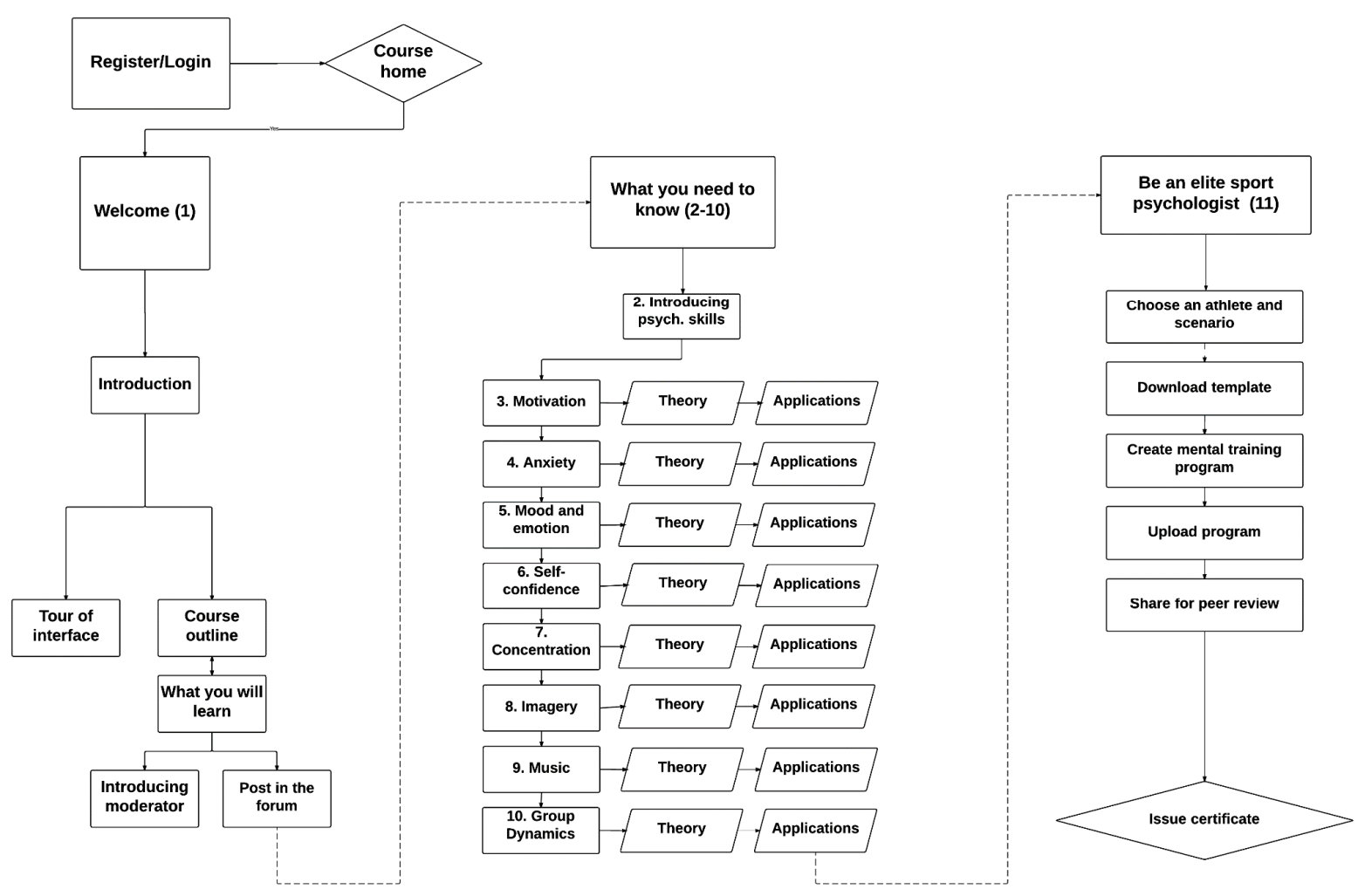

Figure 3. Structured pathway through the course

\section{Designing for autonomy}

\section{Meaningful choice}

The course designer can offer choices to the learner as they navigate their own pathway through the course content, using information that is both meaningful and helpful to the learners. Meaningful choice opportunities occurred throughout the course, with learners being informed that they could engage with as much or as little as they wanted with the learning activities presented, depending on their own interests. Perhaps the clearest example of choice occurred in the final learning activity, where learners designed a mental training program for a hypothetical elite athlete. Eight realistic athlete personas were created, each representing a performer from a specific sport presenting with one or more psychological issues pertinent to the topic areas covered in the course; for example, a golfer with a putting problem that was beginning to adversely affect his mood. Figure 4 provides a screenshot of an example persona. It can be seen that the learner is provided with a brief summary followed by a downloadable detailed description and task. To complete the final task, which was to design a customised mental training program, learners chose one of the eight personas based on their own sporting preferences or a particular therapeutic intervention that interested them. 


\section{Athlete Personas}

Read the personas and download one of your choice.

\section{Denise Flowers - Hurdles}

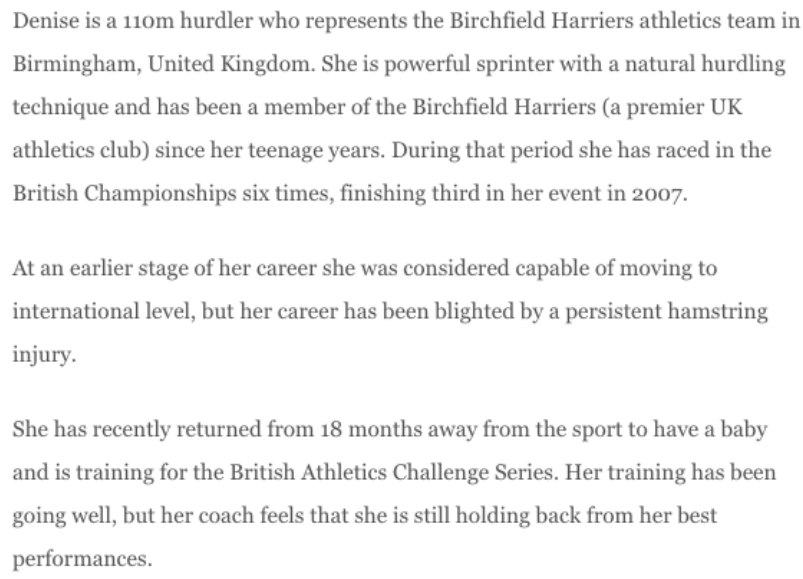

$\underline{\Perp}$ Download persona and task $\bullet \circ \odot \circ \circ \circ 0$
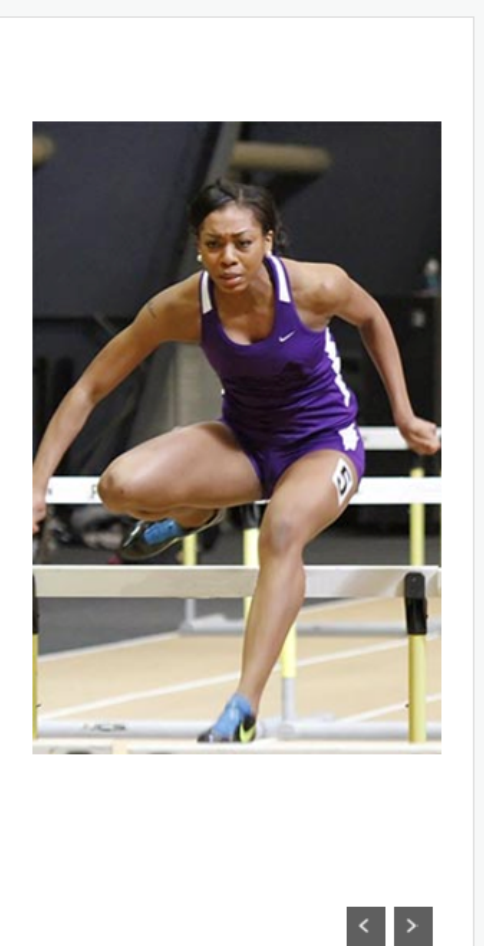

Figure 4. Example persona developed for "Elite Sport Performance: Psychological Perspectives"

\section{Self-paced learning with no weekly deadlines}

The course was designed to remain open for a 4-month period giving learners sufficient time to complete the course, but also leap ahead if they wished to work within a specific time period more suitable to them. This design decision afforded flexibility in approach to the learners' personal time with the aim of sustaining their engagement. The course was designed in such a way that no time-dependent activities were embedded in the course (e.g., group work often seen in other learning settings). This is in line with research by Amabile, DeJong, and Lepper (1976), which offered evidence that the imposition of deadlines undermines intrinsic motivation. Informal learning within a MOOC must integrate with other aspects of learners' lives, and the imposition of deadlines runs the risk of creating unnecessary external pressure, thereby undermining learner intrinsic motivation and increasing the risk of withdrawal if they fall behind. Closure of the course after 4 months represented an artificial but necessary endpoint, for the practical reason that the final data set had to be downloaded and analysed, which was explained to learners from the outset. The course was reopened once data evaluation was completed, allowing learners to continue to access the course materials if they wished.

\section{Limiting task imposition and reward contingencies}

Although the course had a final objective of creating a mental training program, a design requirement was that all tasks were optional, and had appropriate supporting information, a clear purpose, and opportunities for self-reflection to consider concepts in relation to learners' own worldview and experience. Learners were therefore able to choose the activities with which they wished to engage rather than have mandatory tasks. In effect learners were encouraged to follow a path that matched their own interests and levels of enjoyment. Furthermore, reward contingencies such as badges or formal qualifications were absent from the course as they were hypothesised to potentially undermine intrinsic motivation (see Deci, 1971) in this particular learning context. 
Task involvement, immersion, and presence

Task involvement is strongly associated with intrinsic motivation (Papaioannou, Theodosiou, Pashali, \& Digelidis, 2012). When learners are task involved, they undertake an activity because of its inherent qualities. It can be contrasted with ego involvement in which learners place a contingency on their own self-esteem based on performance outcomes - often a feature of traditional education. Immersion is associated with task involvement and feelings of presence in both digital and real-world environments; learners feel less distracted by external stimuli and can fully attend to their immediate surroundings. Immersion is particularly important in digital contexts where high-quality images that draw the eye or professionally produced videos can immerse the learner and thereby foster intrinsic motivation. An example of an immersive and involving task was the concentration grid exercise (Figure 5). The exercise placed the learner in the moment, where their sole focus was on the task at hand. It was developed to allow learners to assess how many numbers they could find on a randomised grid in a 1-minute period, which could be repeated unlimited times to try to improve their personal best score. No value was placed on their score, but rather an explanation was provided to illustrate how difficult it can be to shift attention from one thing to another in a pressurised context, analogous to the conditions experienced in sporting competition.

\begin{tabular}{|c|c|c|c|c|c|c|c|c|c|}
\hline \multicolumn{10}{|c|}{ Activity } \\
\hline \multicolumn{10}{|c|}{ Test your concentration } \\
\hline \multicolumn{10}{|c|}{$\begin{array}{l}\text { How do you focus under pressure? Here's an exercise that tests your skills of concentration by seeing how you } \\
\text { quickly you can find numbers on a grid. In sixty seconds click on the numbers on the grid below in order from } \\
\text { oo-99. How far can you get before a minute is up? }\end{array}$} \\
\hline \multicolumn{10}{|c|}{ Instructions } \\
\hline \multicolumn{10}{|c|}{ 1. Start the stop watch. } \\
\hline \multicolumn{10}{|c|}{ 2. Click/touch on each number. They will turn green if clicked in the right order. } \\
\hline \multicolumn{10}{|c|}{ 3. To have another go click on the restart button remembering to reset the stopwatch again. } \\
\hline \multicolumn{10}{|c|}{$00=00: 30006$} \\
\hline \multicolumn{10}{|c|}{ Pause } \\
\hline 19 & 20 & 22 & 17 & 88 & 66 & 16 & 34 & 83 & 25 \\
\hline 86 & 38 & 74 & 91 & 79 & 77 & 95 & 45 & 35 & 82 \\
\hline 06 & 67 & 21 & 51 & 07 & 43 & 55 & 75 & 76 & 63 \\
\hline 50 & 40 & 26 & 14 & 72 & 44 & 56 & 99 & 48 & 93 \\
\hline 61 & 53 & 94 & 60 & 62 & 31 & 18 & 10 & 27 & 29 \\
\hline 97 & & 81 & 49 & 70 & 58 & 23 & 52 & 39 & 05 \\
\hline 68 & 41 & 89 & 64 & $\mathbf{0 8}$ & 30 & 24 & 09 & 69 & 15 \\
\hline 04 & 65 & 84 & 78 & $\mathbf{0 3}$ & & 13 & 47 & 46 & 54 \\
\hline 87 & 85 & 59 & 90 & 33 & 37 & 92 & 12 & 71 & 32 \\
\hline & 73 & 42 & 57 & 96 & 28 & 36 & 98 & 11 & 80 \\
\hline \multicolumn{10}{|c|}{ RESTART } \\
\hline \multicolumn{10}{|c|}{ How did you do? } \\
\hline \multicolumn{10}{|c|}{ It's not easy is it? Did you find yourself thinking: } \\
\hline \multicolumn{10}{|c|}{ - This is really difficult. } \\
\hline
\end{tabular}

Figure 5. Concentration grid exercise 


\section{Applying design to support competence}

A key design goal to support competence was to facilitate "growing and experiencing challenge to current ability and knowledge" (Baard, 2002, p. 264). The course included techniques to help develop competence, including authentic learning tasks and access to expertise (Herrington, Reeves, \& Oliver, 2010), and a usercentred design approach to creating the course interface (Norman \& Draper, 1986). Features grounded in selfdetermination theory created an online learning environment that offered optimal challenges and encouraged the development and mastery of new skills to be used subsequently in applied contexts.

Supportive information, structure, and clear task rationale

Providing relevant, timely, and supportive information helps to facilitate competence (see Ryan \& Deci, 2017). During the course, learners received:

- content divided into manageable blocks (see Figure 3) and written in an accessible web-friendly style;

- information relevant to navigating the course content;

- instructions on using the course interface;

- $\quad$ supporting information on how to approach a specific learning activity; and

- a clear rationale for all tasks so that learners understood the inherent requirements of the activity.

\section{Optimal challenge}

Designing optimal challenge for a diverse set of learners from different parts of the world in an open online context is difficult to achieve, given that individual baseline knowledge and educational attainment are unknown. However, optimal challenge is an important ingredient in building a perceived sense of competence (Guadagnoli \& Lee, 2004). The design of this course therefore aimed to increase the probability of learners being optimally challenged by:

- developing learner profiles (personas) of potential course registrants;

- providing information on course level and target audience;

- offering opportunities to extend learning via increasing levels of challenge as the course progressed; and

- allowing learners to set their own goals.

For those learners who for any reason were outside of their comfort zone, there were opportunities to seek assistance. For example, a course facilitator was available who responded to queries within 24 hours. More complex questions on the psychology of elite sport performance were forwarded to the course convenor, who had experience of providing psychological support to more than 1000 international and professional performers, including a host of Olympic medallists. Furthermore, learners could communicate with each other via the online forums.

\section{Perceived sense of progression and recognition of success}

A sense of progression by completing tasks also builds a sense of competence (e.g., Ryan, Rigby, \& Przybylski, 2006; Schunk, 2003). This was provided via mechanisms such as a progress bar, motivational messaging, and course communications that recognised success. As learners progressed through the course, they marked each unit of learning as complete. For example, on completion of the mood and emotion module, they clicked the completed button and moved onto the next module. This progress was recorded and reinforced on future logins, allowing learners to progress from where they left off in their previous session.

Emphasis on positive and constructive feedback with unexpected rewards

Self-determination theory focuses on the supporting informational features of a motivational climate to develop competence (see Ryan \& Deci, 2017). Put differently, positive feedback that contains content from which meaning can be constructed is vital in terms of building competence. For example, a sample response from the course convenor is provided below in relation to a task in which learners considered the importance 
of self-talk in emotional regulation. Note how the content of the positive feedback sits alongside its constructive nature:

That's a great point you make about considering how self-talk is delivered rather than just considering the content. "It's not what you say but the way that you say it" so to speak. Definitely something to be considered if working with an elite athlete to improve self-talk.

Close attention was given to the tone and voice of all course communications so that learners would feel that every contribution would be received positively to build rather than undermine a sense of personal efficacy.

In addition, unexpected rewards through a series of weekly merit awards were offered. Unexpected rewards are rewards that are unknown to an individual when they initiate and engage with an activity (Lepper, Greene, \& Nisbett, 1973) and unlike expected rewards do not have an undermining effect on intrinsic motivation (Deci, Koestner, \& Ryan, 1999), but may enhance enjoyment (Tang \& Hall, 1995).

\section{Applying design to support relatedness}

\section{Provide opportunities to connect with others.}

The issue of developing meaningful and close relationships within MOOCs is problematic due to the sheer size of the participant pool. However, offering opportunities for participants to connect was a design feature of the course. The provision of a course forum offered a platform for learners to connect with each other, to share ideas, experiences, opinions and personal insights, and to co-construct knowledge. In addition, the course facilitator helped to weave themes together when responding to discussion points. Contact with the course development team was integrated into the design via responding to requests in the course forum, or via comment boxes or email. In sum, over 800 posts were made. Each learner was personally welcomed to the course and encouraged to contribute to the forums.

Warm interactions and friendly style

Feedback to learners, the language style of course content, and responses to questions were welcoming, respectful, and authentic throughout the course duration. The communication style of the content balanced authority and expertise with a warm and equitable tone that was both inclusive and encouraging. Finally, moderators were provided with guidelines from the course development team to politely request that all course participants to be respectful in their interactions with other learners.

\section{Taking an internal frame of reference of others}

The design incorporated an internal frame of reference (Rogers, 1957), in which the individual context of learners was considered and appreciated. Three design approaches were used to promote an internal frame of reference:

- the creation of learner personas to provide a rich profile of possible users with varying backgrounds, interests, and contexts;

- $\quad$ usability testing to better understand perceptions and possible frustrations when interacting with the course; and

- a warm and caring communication style.

Adopting an internal frame of reference through techniques such as persona creation is an approach commonly used by web professionals to represent models of users of a website as real people. Their main purpose is to act as a reference throughout the design life cycle to illustrate the behaviours, attitudes, and motivations of a website user. Personas can be brought out at different points to help inform the design of the user experience and answer questions like "What would Jane do here? What would she think? Is this going to work?" From a self-determination theory perspective, the creation of personas also offers the designer the opportunity to take the perspective of possible course participants when there is no direct access beforehand. 


\section{Results: Demonstrating the outcomes from the course}

The aim in providing results from the MOOC "Elite Sport Performance: Psychological Perspectives" is to offer preliminary evidence of the success of the design principles, to support further iterations of design research. It should be recognised that any MOOC, by virtue of being open and online, has many uncontrolled variables. Further, this study considered only a single MOOC. As a result, the connection between the results from the course, in terms of engagement and retention, are associated with the framework but cannot necessarily be attributed to it. In following the design-based methodology, we present these results to support further studies that may elaborate upon the principles embodied in the framework.

\section{Course data}

At the official closure of the course, a total of 1007 participants had registered, of whom 745 initiated the course. Web analytics data indicated that learners were from 73 countries. A demographic survey completed by 345 participants is summarised in Table 1 .

Table 1

Profile of course participants $(N=345)$

\begin{tabular}{llll}
\hline Source & Group & $\boldsymbol{n}$ & \% \\
\hline Sex & Male & 202 & 58.6 \\
Age group & Female & 143 & 41.4 \\
& $18-24$ & & \\
& $25-34$ & 67 & 19.4 \\
& $35-44$ & 152 & 44.1 \\
& $45-54$ & 59 & 17.1 \\
& $55-64$ & 43 & 12.5 \\
Education & 65 and over & 19 & 5.5 \\
& & 5 & 1.4 \\
& Less than high school & 3 & 0.9 \\
& High school graduate & 32 & 9.3 \\
& Vocational or foundational qualification & 33 & 9.6 \\
& Undergraduate degree & 116 & 33.6 \\
& Postgraduate degree & 161 & 46.7 \\
\hline
\end{tabular}

Figure 6 provides an overview of course progression, as indicated by the endpoint of participation. Exactly 200 participants completed the course, including the submission of a mental training program (the final assessment), representing a completion rate of $20 \%$. Establishing definitively what constitutes a "successful" completion rate is problematic, although we contend that the typical completion rate reported for MOOCs of $12 \%$ (Jordan, 2015) provides a useful rule of thumb, suggesting that the course had a better-than-average completion rate. Completing participants had finished all modules in sequence before submitting their mental training program and receiving a certificate of completion. A further 71 participants completed all learning modules but chose not to submit a mental training program. If these participants are included, the course completion rate rises to approximately $27 \%$. In addition, using a benchmarking metric proposed by Jordan (2015) in which completion rates are calculated as the proportion of learners who completed the course against the total number of learners who engaged with some learning content (as opposed to those who registered but had no engagement with the course at all), the completion rate is much higher. Restricting the analysis to those who completed at least the introduction module, the completion rate rises to $39 \%$.

It can also be seen that 495 participants (approximately $49 \%$ of all course registrants) had no meaningful engagement, not even progressing to the "Welcome to the Course" page. In total 241 (or 24\%) participants fell somewhere in the middle, or more specifically, engaged with the course to varying degrees without completing the course. These participants range from those who completed the "Welcome to the Course" 
module $(n=115)$ to those who progressed through to complete the later modules of "Concentration", "Imagery", and "Music" $(n=14)$ and therefore engaged to a significant level without reaching the endpoint of the course.

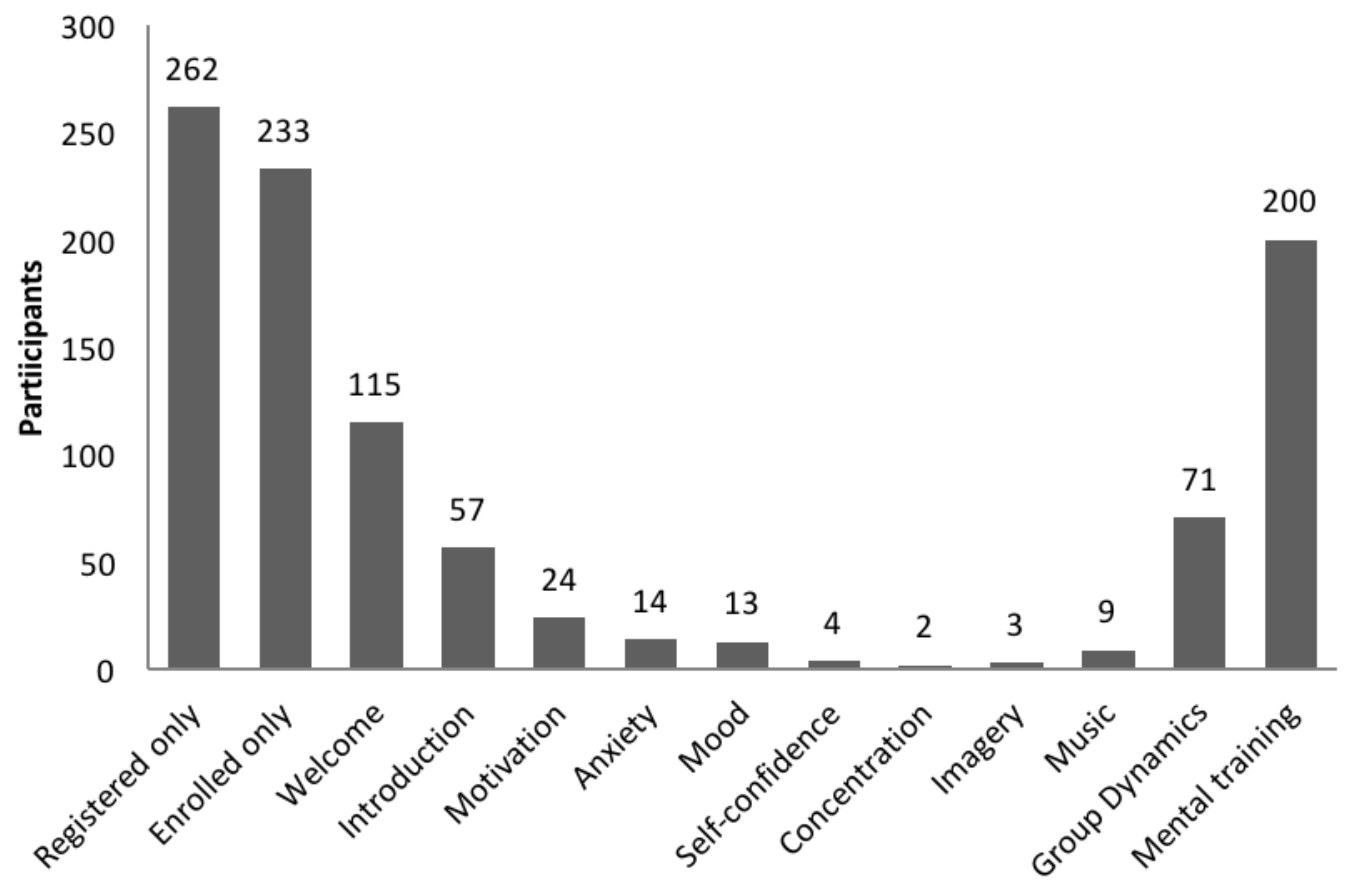

Figure 6. Endpoint of course participation $(N=1007)$

\section{Post-course data}

The post-course survey was administered over a 3-week period from March to April 2016 and sent to course participants who completed or almost completed the course. The post-course survey received 143 responses, using the Intrinsic Motivation Inventory (IMI; Plant \& Ryan, 1985) to assess aspects of intrinsic motivation. The IMI is a flexible and widely used tool that has been used in several innovative experimental contexts (e.g., Hanus \& Fox, 2015). The IMI includes 7 scales to assess constructs related to intrinsic motivation: interest and enjoyment, perceived competence, effort and importance, pressure or tension, perceived choice, and value and usefulness. Two items from each sub-scale were selected and randomised prior to distribution via a Qualtrics online survey. The IMI has a mean internal consistency (Cronbach's alpha) coefficient of .85 (McAuley, Duncan, \& Tammen, 1989). Items were adapted slightly in accordance with the IMI guidelines to better fit the MOOC context. For example, the interest and enjoyment item "I enjoyed doing this activity very much" was modified to "I enjoyed doing this open online course very much". In addition to the 14-item measure, an open-ended question was added for participants to provide qualitative feedback on the course.

Table 2 includes the IMI survey results. Scores were self-reported on a 1-7 scale where lower end scores (i.e., 1-3) represent not at all true, scores around the median (i.e., 3-5) represent somewhat true, and higher end scores (i.e., 5-7) represent very true. High mean scores of $6.03(S D=1.03)$ were reported for enjoyment of the course and 6.26 for interest in the course $(S D=0.85)$. Scores were also high for items related to competence, effort and importance, perceived choice, and value and usefulness. Generally, participants felt relaxed $(M=6.10, S D=1.03)$ and under little pressure $(M=2.41, S D=1.62)$ participating in the course. Scores for relatedness were proportionally lower as reflected in feelings of closeness to other learners $(M=$ $3.13, S D=1.73)$ and wishing to interact with others more often $(M=4.78, S D=1.73)$. Participants reported that several conditions supporting intrinsic motivation were in place, such as an absence of pressure and perceived choice. The data provide evidence of high-quality motivation and a needs-supportive environment. Learners felt competent, found the course useful and personally important, and were willing to put in effort. 
Finally, the proximal role of relatedness was proportionally lower, but apparently less important to overall engagement in this particular context.

Table 2

Mean item scores for the intrinsic motivation inventory $(N=143)$

\begin{tabular}{llll}
\hline Measure & Item & $\boldsymbol{M}$ & $\boldsymbol{S D}$ \\
\hline Interest and enjoyment & I enjoyed doing this open online course very much. & 6.03 & 1.03 \\
& I would describe this open online course as very interesting. & 6.26 & 0.85 \\
Perceived competence & I am satisfied with my performance in this open online course. & 5.23 & 1.39 \\
& After working on this open online course for a while, I felt & 5.59 & 1.21 \\
& pretty competent. & 5.08 & 1.51 \\
Effort and importance & I put a lot of effort into this open online course. & 5.27 & 1.52 \\
& It was important to me to do well in this open online course. & 6.10 & 1.03 \\
Pressure and tension & I was very relaxed in doing this open online course. & 2.41 & 1.62 \\
& I felt pressured while doing this open online course. & 5.99 & 1.13 \\
Perceived choice & I believe I had some choice about doing this open online & 6.34 & 0.98 \\
& course. & 6.16 & 0.94 \\
Value and usefulness & I did this open online course because I wanted to. & \\
& I believe this open online course could be of some value to & 6.20 & 0.92 \\
& me. & I believe doing this open online course could be beneficial to & \\
Relatedness & me. & I'd like a chance to interact with people more often in this & 4.78 \\
& open online course. & 3.50
\end{tabular}

Sample responses to the open-ended question are provided in Table 3, which offer further evidence of intrinsic motivation among those who engaged with the course. Responses are grouped under themes derived from a content analysis, used here to categorise course engagement.

Table 3

Example responses to open-ended question in engagement survey $(n=76)$

\begin{tabular}{ll}
\hline Feedback & Example response \\
\hline Recommend to others & $\begin{array}{l}\text { Aside from myself, I was also able to introduce this course to my sporting } \\
\text { fraternity who were interested in doing Sport Psychology. (Learner 83, Singapore) } \\
\text { Gratitude and praise }\end{array}$ \\
$\begin{array}{l}\text { My impressions about the course are very positive. You developed and unselfishly } \\
\text { shared very innovative and interactive course among sport and exercise } \\
\text { psychology community. I was very much pleased and thankful for being part of it. } \\
\text { (Learner 248, Serbia) }\end{array}$ \\
$\begin{array}{l}\text { I found the references to real life example, video clips, etc. most interesting. } \\
\text { Interest and enjoyment }\end{array}$ \\
$\begin{array}{l}\text { Useful and beneficial } \\
\text { I am a psychologist working in general practice and often see people who are } \\
\text { struggling to reach their performance goals in sport or in work or in other areas of } \\
\text { life. This course really brought together the theoretical and practical aspects of } \\
\text { psychology in a way that helped me to formulate a cohesive approach to helping } \\
\text { these people. (Learner 1010, Australia) }\end{array}$ \\
\hline
\end{tabular}




\section{Discussion}

The evaluation data for "Elite Sport Performance: Psychological Perspectives" provides evidence of a MOOC that appears to have sustained activity and produced strong engagement. The creation and submission of a mental training program, for example, represented a genuine commitment on the part of learners, especially considering that they received no formal qualification beyond a certificate of completion for completing the course. The so-called funnel of participation (Clow, 2013) was evident in this course, with more than 1000 participants registering for the course, but only 271 completing the final course module and 200 submitting a mental training program.

Self-report data collected from a post-course survey of participants provided evidence of intrinsic motivation, engagement, and positive learner sentiment towards the course. The positive responses to the course engagement questionnaire and additional qualitative data were encouraging, and contained emergent themes of interest and enjoyment, perceived competence, autonomy support, and individual learning. Furthermore, many participants expressed praise and gratitude towards the course, possibly because they had received a high-quality learning experience at no financial cost and appreciated the efforts of the course team. Data from the IMI survey suggested that participants felt that their autonomy and competence needs were supported by the course to a large degree, although it is notable that while participants did feel relatedness they felt it to a lesser degree. Achieving relatedness within MOOCs is a continuing challenge for learning designers, which was evident in the present course and is consistent with the findings of Durksen et al. (2016).

Our aim in this paper was to use a theory-based approach, grounded in self-determination theory, to consider how engagement might be nurtured within MOOCS - a learning environment where participants may choose to leave at any time and where dropout is a normative event. Using self-determination theory, a framework was articulated for how learning designers might support the three basic psychological needs of autonomy, competence, and relatedness to help foster intrinsic motivation for open online learning. This framework does not, in a point of difference from other frameworks for MOOCS, address learning directly - rather, it posits principles for improving engagement, motivation, and retention.

A design-based methodology has been followed, and this work represents a first iteration in which design principles have been formulated and tested in a real-world situation with 1007 course participants. The results support further application of the framework to see whether the findings are repeatable and generalisable to other contexts. A necessary consideration in future research is the role of learning designers. In the present study the researchers themselves, with learning design experience, attempted to implement the framework. In future studies, it is recommended that learning designers external to the research team are recruited to test how applicable the framework is to learning designers who do not have in-depth familiarity with the principles upon which it is based.

Evaluating the application of a psychological theory in an open online educational environment has significant challenges and limitations. The environment in which the research was conducted was dynamic and involved real-world activity as opposed to experimental conditions, and included a diverse cohort of learners. Future research would benefit from examining learner diversity and issues pertinent to broader life goals and well-being outcomes when engaging in MOOCs in a completely autonomous way. Further examples of direct measurement of needs satisfaction in line with design principles are required. However, despite these potential limitations, the central argument for the utility of the framework rests upon its consonance with a well-established theory of motivation and the existing learning design literature.

An important aspect of MOOC design that has not been addressed in this paper, but nevertheless is a vital component, is the aesthetic properties (e.g., clean interface, high-quality images) and user experience (e.g., speed of access, ease of navigation) of interacting with the learning interface. We would recommend incorporating some best practice in user-centred design techniques to attempt to optimise the user experience. This project drew on the recommendations of Krug (2014), Norman and Draper (1986), and Peters (2014). Quality interface design will be crucial in engaging and sustaining learner involvement in MOOCs. 
Designing for MOOCs presents a unique challenge due to the diverse range of learner contexts, lack of formal extrinsic motivational factors, and challenges to learner engagement. This paper has proposed that selfdetermination theory has a strong foundation within the literature as a basis for fostering the intrinsic motivation of learners. We have proposed that it could be applied to the context of MOOC learning design to serve as a guide for creating courses that support autonomy, competence, and relatedness, and have presented a framework that details strategies for how this can be realised. Autonomy can be encouraged by creating pathways that involve meaningful choice and limited extrinsic pressures. Competence can be promoted by offering a structured environment that presents real-world challenges and opportunities for mastery without the high-stakes evaluation of traditional education. Relatedness can be achieved by providing a climate that offers warmth and opportunities for connection, although this remains a challenge for learning designers.

The development of "Elite Sport Performance: Psychological Perspectives" demonstrates a real-world example of how a self-determination theory design framework can be applied. An evaluation of the course has shown how each of these design principles for open online learning can be implemented. Findings support the need for further research into the potential for the framework to be utilised in broader contexts to improve intrinsic motivation, engagement, and retention.

\section{References}

Adie, J. W., Duda, J. L., \& Ntoumanis, N. (2008). Autonomy support, basic need satisfaction and the optimal functioning of adult male and female sport participants: A test of basic needs theory. Motivation and Emotion, 32(3), 189-199. https://doi.org/10.1007/s11031-008-9095-z

Amabile, T. M., DeJong, W., \& Lepper, M. R. (1976). Effects of externally imposed deadlines on subsequent intrinsic motivation. Journal of Personality and Social Psychology, 34(1), 92-98. https://doi.org/10.1037/0022-3514.34.1.92

Baard, P. P. (2002). Intrinsic need satisfaction in organizations: A motivational basis of success in for-profit and not-for-profit settings. In E. L. Deci \& R. M. Ryan (Eds.), Handbook of self-determination research (pp. 255-275). Rochester, NY: The University of Rochester Press.

Bandura, A. (1995). Exercise of personal and collective efficacy in changing societies. Self-efficacy in changing societies (pp. 1-46). Cambridge: Cambridge University Press.

Barab, S., \& Squire, K. (2004). Design-based research: Putting a stake in the ground. The Journal of the Learning Sciences, 13(1), 1-14. https://doi.org/10.1207/s15327809jls1301_1

Barak, M., Watted, A., \& Haick, H. (2016). Motivation to learn in massive open online courses: Examining aspects of language and social engagement. Computers \& Education, 94, 49-60. https://doi.org/10.1016/j.compedu.2015.11.010

Baumeister, R. F., \& Leary, M. R. (1995). The need to belong: Desire for interpersonal attachments as a fundamental human motivation. Psychological Bulletin, 117(3), 497-529. https://doi.org/10.1037/00332909.117.3.497

Beaven, T., Codreanu, T., \& Creuzé, A. (2014). Motivation in a language MOOC: issues for course designers. In E. Martín-Monje \& E. Bárcena (Eds.), Language MOOCs: Providing learning, transcending boundaries (pp. 48-66). Berlin: De Gruyter Open.

Beaven, T., Hauck, M., Comas-Quinn, A., Lewis, T., \& de los Arcos, B. (2014). MOOCs: Striking the right balance between facilitation and self-determination. MERLOT Journal of Online Learning and Teaching, 10(1), 31-43. https://doi.org/10.1080/08870446.2011.613995

Black, A. E., \& Deci, E. L. (2000). The effects of instructors' autonomy support and students' autonomous motivation on learning organic chemistry: A self-determination theory perspective. Science Education, 84(6), 740-756. https://doi.org/10.1002/1098-237X(200011)84:6<740::AID-SCE4>3.0.CO;2-3

Britton, P. C., Patrick, H., Wenzel, A., \& Williams, G. C. (2011). Integrating motivational interviewing and self-determination theory with cognitive behavioral therapy to prevent suicide. Cognitive and Behavioral Practice, 18(1), 16-27. https://doi.org/10.1016/j.cbpra.2009.06.004

Chen, K.-C., \& Jang, S.-J. (2010). Motivation in online learning: Testing a model of self-determination theory. Computers in Human Behavior, 26(4), 741-752. https://doi.org/10.1016/j.chb.2010.01.011 
Clow, D. (2013, April). MOOCs and the funnel of participation. In D. Suthers, K. Verbert, E. Duval, \& X. Ochoa (Eds.), LAK '13. Proceedings of the Third International Conference on Learning Analytics and Knowledge (pp. 185-189). New York, NY: ACM. https://doi.org/10.1145/2460296.2460332

Cobb, P., Confrey, J., diSessa, A., Lehrer, R., \& Schauble, L. (2003). Design experiments in educational research. Educational Researcher, 32(1), 9-13. https://doi.org/10.3102/0013189X032001009

Collins, A., Joseph, D., \& Bielaczyc, K. (2004). Design research: Theoretical and methodological issues. The Journal of the Learning Sciences, 13(1), 15-42. https://doi.org/10.1207/s15327809jls1301_2

de Barba, P. G., Kennedy, G. E., \& Ainley, M. D. (2016). The role of students' motivation and participation in predicting performance in a MOOC. Journal of Computer Assisted Learning, 32(3), 218-231. https://doi.org/10.1111/jcal.12130

Deci, E. L. (1971). Effects of externally mediated rewards on intrinsic motivation. Journal of Personality and Social Psychology, 18(1), 105-115. https://doi.org/10.1037/h0030644

Deci, E. L. (1975). Intrinsic motivation. New York, NY: Plenum Press. https://doi.org/10.1007/978-1-46134446-9

Deci, E. L., Koestner, R., \& Ryan, R. M. (1999). A meta-analytic review of experiments examining the effects of extrinsic rewards on intrinsic motivation. Psychological Bulletin, 125(6), 627-668. https://doi.org/10.1037/0033-2909.125.6.627

Deci, E. L., \& Ryan, R. M. (2000). The "what" and "why" of goal pursuits: Human needs and the selfdetermination of behavior. Psychological Inquiry, 11(4), 227-268. https://doi.org/10.1207/S15327965PLI1104_01

Deci, E. L., \& Ryan, R. M. (2002). Overview of self-determination theory: An organismic dialectical perspective. In E. L. Deci \& R. M. Ryan (Eds.), Handbook of self-determination research (pp. 3-33). Rochester, NY: University of Rochester Press.

Deci, E. L., \& Ryan, R. M. (2010). Self-determination. In I. B. Weiner \& W. E. Craighead (Eds.), Corsini encyclopedia of psychology (4th ed., pp. 1-2). London: John Wiley \& Sons.

Deci, E. L., \& Ryan, R. M. (2014). Autonomy and need satisfaction in close relationships: Relationships motivation theory. In N. Weinstein (Ed.), Human motivation and interpersonal relationships (pp. 53-73). New York, NY: Springer.

Deci, E. L., \& Ryan, R. M. (2016). Optimizing students' motivation in the era of testing and pressure: A selfdetermination theory perspective. In C. W. Liu, K. J. C. Wang, \& M. R. Ryan (Eds.), Building autonomous learners: Perspectives from research and practice using self-determination theory (pp. 9-29). Singapore: Springer. https://doi.org/10.1007/978-981-287-630-0_2

Downes, S. (2009, February 24). Connectivist dynamics in communities [Web log post]. Half an Hour. Retrieved from http://halfanhour.blogspot.com.au/2009/02/connectivist-dynamics-in-communities.html

Downes, S. (2013, May 13). Week 2: The quality of massive open online courses by Stephen Downes. MOOC Quality Project. Retrieved from https://web.archive.org/web/20160317102343/http://mooc.efquel.org:80/week-2-the-quality-of-massiveopen-online-courses-by-stephen-downes/

Durksen, T. L., Chu, M.-W., Ahmad, Z. F., Radil, A. I., \& Daniels, L. M. (2016). Motivation in a MOOC: A probabilistic analysis of online learners' basic psychological needs. Social Psychology of Education, 19(2), 241-260. https://doi.org/10.1007/s11218-015-9331-9

Ferguson, R., Clow, D., Beale, R., Cooper, A. J., Morris, N., Bayne, S., \& Woodgate, A. (2015). Moving through MOOCS: Pedagogy, learning design and patterns of engagement. In G. Conole, T. Klobučar, C. Rensing, J. Konert, \& É. Lavoué (Eds.), Design for Teaching and Learning in a Networked World. Proceedings of the 10th European Conference on Technology Enhanced Learning (pp. 70-84). Cham: Springer International Publishing. https://doi.org/10.1007/978-3-319-24258-3 6

Gagné, M., Forest, J., Vansteenkiste, M., Crevier-Braud, L., van den Broeck, A., Aspeli, A. K., ... Westbye, C. (2015). The multidimensional work motivation scale: Validation evidence in seven languages and nine countries. European Journal of Work and Organizational Psychology, 24(2), 178-196. https://doi.org/10.1080/1359432X.2013.877892

Guadagnoli, M. A., \& Lee, T. D. (2004). Challenge point: A framework for conceptualizing the effects of various practice conditions in motor learning. Journal of Motor Behavior, 36(2), 212-224.

https://doi.org/10.3200/JMBR.36.2.212-224 
Guàrdia, L., Maina, M., \& Sangrà, A. (2013). MOOC design principles: A pedagogical approach from the learner's perspective. eLearning Papers, 33. Retrieved from http://r-libre.teluq.ca/596/1/Indepth 33 4.pdf

Guay, F., Ratelle, C. F., \& Chanal, J. (2008). Optimal learning in optimal contexts: The role of selfdetermination in education. Canadian Psychology/Psychologie canadienne, 49(3), 233-240. https://doi.org/10.1037/a0012758

Gütl, C., Rizzardini, R. H., Chang, V., \& Morales, M. (2014). Attrition in MOOC: Lessons learned from drop-out students. In L. Uden, J. Sinclair, Y.-H. Tao, \& D. Liberona (Eds.), Learning Technology for Education in Cloud: MOOC and Big Data. Proceedings of the Third International Workshop (pp. 37-48). Cham: Springer International Publishing.

Hanus, M. D., \& Fox, J. (2015). Assessing the effects of gamification in the classroom: A longitudinal study on intrinsic motivation, social comparison, satisfaction, effort, and academic performance. Computers \& Education, 80, 152-161. https://doi.org/10.1016/j.compedu.2014.08.019

Herrington, J., Reeves, T. C., \& Oliver, R. (2010). A guide to authentic e-learning. New York, NY: Routledge. https://doi.org/10.4324/9780203864265

Hew, K. F. (2016). Promoting engagement in online courses: What strategies can we learn from three highly rated MOOCS. British Journal of Educational Technology, 47(2), 320-341. https://doi.org/10.1111/bjet.12235

Jang, H., Reeve, J., \& Halusic, M. (2016). A new autonomy-supportive way of teaching that increases conceptual learning: Teaching in students' preferred ways. The Journal of Experimental Education, 84(4), 686-701. https://doi.org/10.1080/00220973.2015.1083522

Jordan, K. (2015). Massive open online course completion rates revisited: Assessment, length and attrition. The International Review of Research in Open and Distributed Learning, 16(3), 341-358. https://doi.org/10.19173/irrodl.v16i3.2112

Khan, I. U., Hameed, Z., Yu, Y., Islam, T., Sheikh, Z., \& Khan, S. U. (2017). Predicting the acceptance of MOOCs in a developing country: Application of task-technology fit model, social motivation, and selfdetermination theory. Telematics and Informatics. http://doi.org/10.1016/j.tele.2017.09.009

Krug, S. (2014). Don't make me think, revisited! A common sense approach to web usability (3rd ed.). Berkeley, CA: New Riders Publishing.

La Guardia, J. G., \& Patrick, H. (2008). Self-determination theory as a fundamental theory of close relationships. Canadian Psychology/Psychologie canadienne, 49(3), 201-209. https://doi.org/10.1037/a0012760

Lepper, M. R., Greene, D., \& Nisbett, R. E. (1973). Undermining children's intrinsic interest with extrinsic reward: A test of the "overjustification" hypothesis. Journal of Personality and Social Psychology, 28(1), 129-137. https://doi.org/10.1037/h0035519

Margaryan, A., Bianco, M., \& Littlejohn, A. (2015). Instructional quality of Massive Open Online Courses (MOOCs). Computers \& Education, 80, 77-83. https://doi.org/10.1016/j.compedu.2014.08.005

Martin, N. I. (2017). Development and evaluation of an open online course in sport psychology using selfdetermination theory principles (Doctoral dissertation). University of Southern Queensland, Australia. Retrieved from https://eprints.usq.edu.au/32882/

Marzouk, Z., Rakovic, M., Liaqat, A., Vytasek, J., Samadi, D., Stewart-Alonso, J., ... Nesbit, J. C. (2016). What if learning analytics were based on learning science? Australasian Journal of Educational Technology, 32(6), 1-18. https://doi.org/10.14742/ajet.3058

Matosic, D., Ntoumanis, N., Boardley, I. D., Sedikides, C., Stewart, B. D., \& Chatzisarantis, N. (2017). Narcissism and coach interpersonal style: A self-determination theory perspective. Scandinavian Journal of Medicine \& Science in Sports, 27(2), 254-261. https://doi.org/10.1111/sms.12635

McAuley, E., Duncan, T., \& Tammen, V. V. (1989). Psychometric properties of the Intrinsic Motivation Inventory in a competitive sport setting: A confirmatory factor analysis. Research Quarterly for Exercise and Sport, 60(1), 48-58. https://doi.org/10.1080/02701367.1989.10607413

Ng, J. Y. Y., Ntoumanis, N., Thogersen-Ntoumani, C., Deci, E. L., Ryan, R. M., Duda, J. L., \& Williams, G. C. (2012). Self-determination theory applied to health contexts: A meta-analysis. Perspectives on Psychological Science, 7(4), 325-340. https://doi.org/10.1177/1745691612447309 
Niemiec, C. P., \& Ryan, R. M. (2009). Autonomy, competence, and relatedness in the classroom Applying self-determination theory to educational practice. Theory and Research in Education, 7(2), 133-144. https://doi.org/10.1177/1477878509104318

Niven, A. G., \& Markland, D. (2016). Using self-determination theory to understand motivation for walking: Instrument development and model testing using Bayesian structural equation modelling. Psychology of Sport and Exercise, 23, 90-100. https://doi.org/10.1016/j.psychsport.2015.11.004

Norman, D. A., \& Draper, S. W. (1986). User centered system design; New perspectives on human-computer interaction. Hillsdale, NJ: L. Erlbaum Associates Inc.

Papaioannou, P., Theodosiou, A., Pashali, M., \& Digelidis, N. (2012). Advancing task involvement, intrinsic motivation and metacognitive regulation in physical education classes: The self-check style of teaching makes a difference. Advances in Physical Education, 2(3), 110-118. https://doi.org/10.4236/ape.2012.23020

Peters, D. (2014). Interface design for learning: Design strategies for learning experiences. Berkeley, CA: New Riders Publishing.

Plant, R. W., \& Ryan, R. M. (1985). Intrinsic motivation and the effects of self-consciousness, self-awareness, and ego-involvement: An investigation of internally controlling styles. Journal of Personality, 53(3), 435449. https://doi.org/10.1111/j.1467-6494.1985.tb00375.x

Reeve, J., \& Lee, W. (2014). Students' classroom engagement produces longitudinal changes in classroom motivation. Journal of Educational Psychology, 106(2), 527-540. https://doi.org/10.1037/a0034934

Rogers, C. R. (1957). The necessary and sufficient conditions of therapeutic personality change. Journal of Consulting Psychology, 21(2), 95-103. https://doi.org/10.1037/h0045357

Rogers, R. (2017). The motivational pull of video game feedback, rules, and social interaction: Another selfdetermination theory approach. Computers in Human Behavior, 73, 446-450. https://doi.org/10.1016/j.chb.2017.03.048

Roth, G., Ron, T., \& Benita, M. (2009). Mothers' parenting practices and adolescents' learning from their mistakes in class: The mediating role of adolescent's self-disclosure. Learning and Instruction, 19(6), 506-512. https://doi.org/10.1016/j.learninstruc.2008.10.001

Ryan, R. M., \& Deci, E. L. (2001). On happiness and human potentials: A review of research on hedonic and eudaimonic well-being. Annual Review of Psychology, 52(1), 141-166. https://doi.org/10.1146/annurev.psych.52.1.141

Ryan, R. M., \& Deci, E. L. (2009). Promoting self-determined school engagement: Motivation, learning, and well-being. In K. R. W. A. Wigfield (Ed.), Handbook of motivation at school (pp. 171-195). New York, NY: Routledge.

Ryan, R. M., \& Deci, E. L. (2017). Basic psychological needs in motivation, development, and wellness. New York, NY: Guilford Press.

Ryan, R. M., Huta, V., \& Deci, E. (2008). Living well: a self-determination theory perspective on eudaimonia. Journal of Happiness Studies, 9(1), 139-170. https://doi.org/10.1007/s10902-006-9023-4

Ryan, R. M., Rigby, C. S., \& Przybylski, A. (2006). The motivational pull of video games: A selfdetermination theory approach. Motivation and Emotion, 30(4), 344-360. https://doi.org/10.1007/s11031$\underline{006-9051-8}$

Salmon, G., Pechenkina, E., Chase, A.-M., \& Ross, B. (2017). Designing massive open online courses to take account of participant motivations and expectations. British Journal of Educational Technology, 48(6), 1284-1294. https://doi.org/10.1111/bjet.12497

Sarrazin, P. G., Tessier, D. P., Pelletier, L. G., Trouilloud, D. O., \& Chanal, J. P. (2006). The effects of teachers' expectations about students' motivation on teachers' autonomy-supportive and controlling behaviors. International Journal of Sport and Exercise Psychology, 4(3), 283-301. https://doi.org/10.1080/1612197X.2006.9671799

Schunk, D. H. (2003). Self-efficacy for reading and writing: influence of modeling, goal setting, and selfevaluation. Reading \& Writing Quarterly, 19(2), 159-172. https://doi.org/10.1080/10573560308219

Sheldon, K. M. (1995). Creativity and self-determination in personality. Creativity Research Journal, 8(1), 25-36. https://doi.org/10.1207/s15326934crj0801_3

Simpson, O. (2008). Motivating learners in open and distance learning: do we need a new theory of learner support? Open Learning: The Journal of Open, Distance and e-Learning, 23(3), 159-170.

https://doi.org/10.1080/02680510802419979 
Sørebø, Ø., Halvari, H., Gulli, V. F., \& Kristiansen, R. (2009). The role of self-determination theory in explaining teachers' motivation to continue to use e-learning technology. Computers \& Education, 53(4), 1177-1187. https://doi.org/10.1016/j.compedu.2009.06.001

Stake, R. (1995). The art of case study design. Thousand Oaks, CA: Sage.

Tang, S.-H., \& Hall, V. C. (1995). The overjustification effect: A meta-analysis. Applied Cognitive Psychology, 9(5), 365-404. https://doi.org/10.1002/acp.2350090502

Terry P. C., \& Martin N. I. (2015). Elite sport performance: Psychological perspectives. Retrieved from http://elitesportpsy.org.au

Tschofen, C., \& Mackness, J. (2012). Connectivism and dimensions of individual experience. The International Review of Research in Open and Distance Learning, 13(1), 124-143. Retrieved from http://www.irrodl.org/index.php/irrodl/article/view/1143/2086

Vansteenkiste, M., Simons, J., Lens, W., Sheldon, K. M., \& Deci, E. L. (2004). Motivating learning, performance, and persistence: The synergistic effects of intrinsic goal contents and autonomy-supportive contexts. Journal of Personality and Social Psychology, 87(2), 246-260. https://doi.org/10.1037/0022$\underline{3514.87 .2 .246}$

Veletsianos, G., \& Shepherdson, P. (2016). A systematic analysis and synthesis of the empirical MOOC literature published in 2013- 2015. International Review of Research in Open \& Distance Learning, 17(2), 198-221. https://doi.org/ 10.19173/irrodl.v17i2.2448

Yousef, A. M. F., Chatti, M. A., Schroeder, U., \& Wosnitza, M. (2014). What drives a successful MOOC? An empirical examination of criteria to assure design quality of MOOCs. In Proceedings of the 2014 IEEE 14th International Conference on Advanced Learning Technologies (pp. 44-48). Athens: IEEE. https://doi.org/10.1109/icalt.2014.23

White, R. W. (1959). Motivation reconsidered: The concept of competence. Psychological Review, 66(5), 297-333. https://doi.org/10.1037/h0040934

Zhou, M. (2016). Chinese university students' acceptance of MOOCs: A self-determination perspective. Computers \& Education, 92-93, 194-203. https://doi.org/10.1016/j.compedu.2015.10.012

Corresponding author: Neil Martin, neil.martin@usq.edu.au

Australasian Journal of Educational Technology (c) 2018.

Please cite as: Martin, N. I., Kelly, N., \& Terry, P. C. (2018). A framework for self-determination in massive open online courses: Design for autonomy, competence, and relatedness. Australasian Journal of Educational Technology, 34(2), 35-55. https://doi.org/10.14742/ajet.3722 